\title{
Reliability Evaluation of Direct Current Distribution System for Intelligent Buildings Based on Big Data Analysis
}

\author{
Chenxi JIA*, Hongyuan DING, Xing ZHANG
}

\begin{abstract}
In intelligent buildings, the power is distributed in the direct current (DC) mode, which is more energy-efficient than the traditional alternating current (AC) mode. However, the DC distribution system for intelligent buildings faces many problems, such as the stochasticity and intermittency of distributed generation, as well as the uncertain reliability of key supply and distribution devices. To solve these problems, this paper evaluates and predicts the reliability of the DC distribution system for intelligent buildings through big data analysis. Firstly, the authors identified the sources of the big data on DC distribution system for reliability analysis, and constructed a scientific evaluation index system. Then, association rules were mined from the original data on the evaluation indices with MapReduce, and a reliability evaluation model was established based on Bayesian network. Finally, the proposed model was proved valid through experiments. The research provides reference for reliability evaluation of the $\mathrm{DC}$ distribution system in various fields.
\end{abstract}

Keywords: big data; direct current (DC) distribution; intelligent buildings; mapreduce; reliability evaluation

\section{INTRODUCTION}

Recent years have witnessed the proliferation of the Internet of things (IoT) and the rapid development of the IoT technologies. This stimulates a growing demand for internal-external information exchange, safety, comfort, convenience, and energy conservation of buildings [1-4]. Focusing on user experience, intelligent buildings have set an energy-saving trend in the building industry. As long as the power supply is configured reasonably, intelligent buildings will achieve the energy-saving goal of green building design [5-7].

The energy efficiency of intelligent buildings can be magnified by direct current (DC) distribution. Compared with the traditional alternating current (AC) distribution mode, the DC distribution mode makes electric energy controllable, and facilitates the access of electronic devices, and distributed power sources, such as wind turbines and photovoltaic (PV) devices. The DC distribution system has great advantages in energy conservation and supply efficiency [8-10].

The domestic research on DC distribution system has just started. Most of the existing studies focus on topological design, key device control, and energy management, with inadequate research into system reliability [11-14]. By the minimum cut-set method, Shi et al. [15] qualitatively analyzed the reliability of DC distribution system, and proved through experiments that equipment-level redundancy design brings a better DC distribution reliability than component-level redundancy design. Li [16] compared DC and AC distribution systems, which contain PV power, under different strategies for energy coordination, evaluated the reliability of each system through failure mode and consequence analysis, as well as sequential Monte Carlo simulation, and drew an important conclusion: without considering the processing features of distributed generation and its impact on distribution system, the AC distribution system is more reliable than the DC distribution system. He et al. [17] simulated the power supply of four DC distribution modes on MATLAB, using the coordinated supply strategy for $\mathrm{AC}$ power source, distributed generation, and energy storage devices, and used the traditional reliability index to measure the reliability of the DC distribution systems with ring structure or the two-end structure.
Thanks to the progress in information technology, big data technology has been widely adopted by many industries. The reliability of the distribution system could be effectively enhanced, if big data management is integrated with the distribution system operation to mine the massive data collected by power detectors and sensors [18-21]. Through association analysis and clustering optimization, Wang et al. [22] determined the relationship between historical states and fault features of devices, and established a multi-dimensional evaluation index system for reliability evaluation of the power system, based on the difference evaluation results of electronic devices. Relying on principal component analysis (PCA) and association analysis, Gerber et al. [23] extracted, examined, and evaluated the faults and defects of electronic devices, obtained the key characteristic parameters of the fault devices, combined them into a parameter set, and evaluated the reliability of the distribution system through parameter weighting and thresholding. To realize effective and accurate reliability evaluation of the distribution system, Emjedi et al. [24] combined big data algorithms like clustering and association analysis with simulation strategies like Monte Carlo method, Bayesian network, and Markov model, and incorporated highly repetitive fault features and fault factors into the reliability index. Moshkbar-Bakhshayesh et al. [25] coupled Monte Carlo method with neural network to collect decentralized and adaptive input data, and proved that this hybrid method supports faster evaluation than sampling a single form of input data.

The DC distribution system for intelligent buildings faces many problems, such as the stochasticity and intermittency of distributed generation, as well as the uncertain reliability of key supply and distribution devices. To solve these problems, this paper designs a reliability evaluation algorithm of the DC distribution system for intelligent buildings, drawing on the merits of big data mining in data analysis and processing. After the big data analysis, a reliability evaluation model was established for the DC distribution system in intelligent buildings.

The rest of this paper is organized as follows: Section 2 enumerates the sources of the big data on the DC distribution system, defines technical route for reliability evaluation, constructs an evaluation index system from the level and degree dimensions, and determines the key 
indices through the PCA; Section 3 mines the association rules from the original data on the evaluation indices with MapReduce; Section 4 sets up a reliability evaluation model established based on Bayesian network, and explains the workflow for evaluating the reliability of DC distribution system in intelligent buildings; Section 5 demonstrates the effectiveness of our model through experiments; Section 6 summarizes the research findings.

\section{EVALUATION INDEX SYSTEM \\ 2.1 Big Data Sources}

Traditional buildings usually adopt the AC distribution mode, which has a low supply reliability and a poor power quality. Besides, power users are in desperate need of intelligent and high-quality power supply. Therefore, it is necessary to design the supply structure for intelligent buildings rationally by optimizing the relevant devices, while controlling the distribution cost. The DC distribution system for intelligent buildings can improve the supply reliability in two aspects:

(1) From the angle of the large grid, the system ensures the supply stability in the large grid, laying the basis for long-term, centralized, and intelligent supply and distribution for $\mathrm{AC} / \mathrm{DC}$ micro grids.

(2) From the angle of users, the system enhances the quality and reliability of local power supply, and provides customized, decentralized, and intelligent supply and distribution for users.

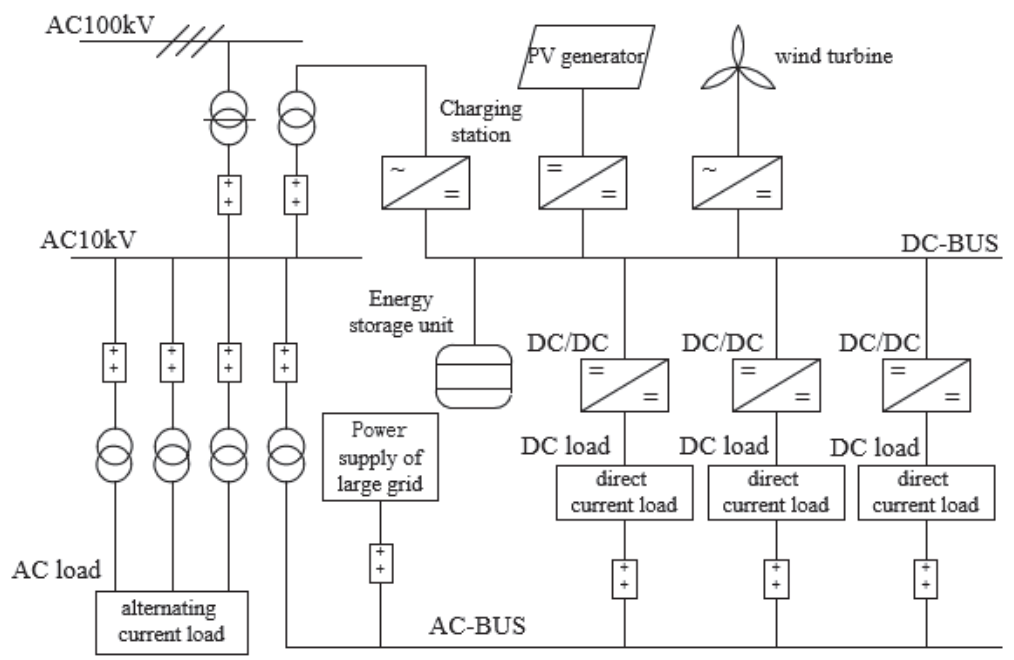

Figure $1 \mathrm{DC}$ distribution system for intelligent buildings

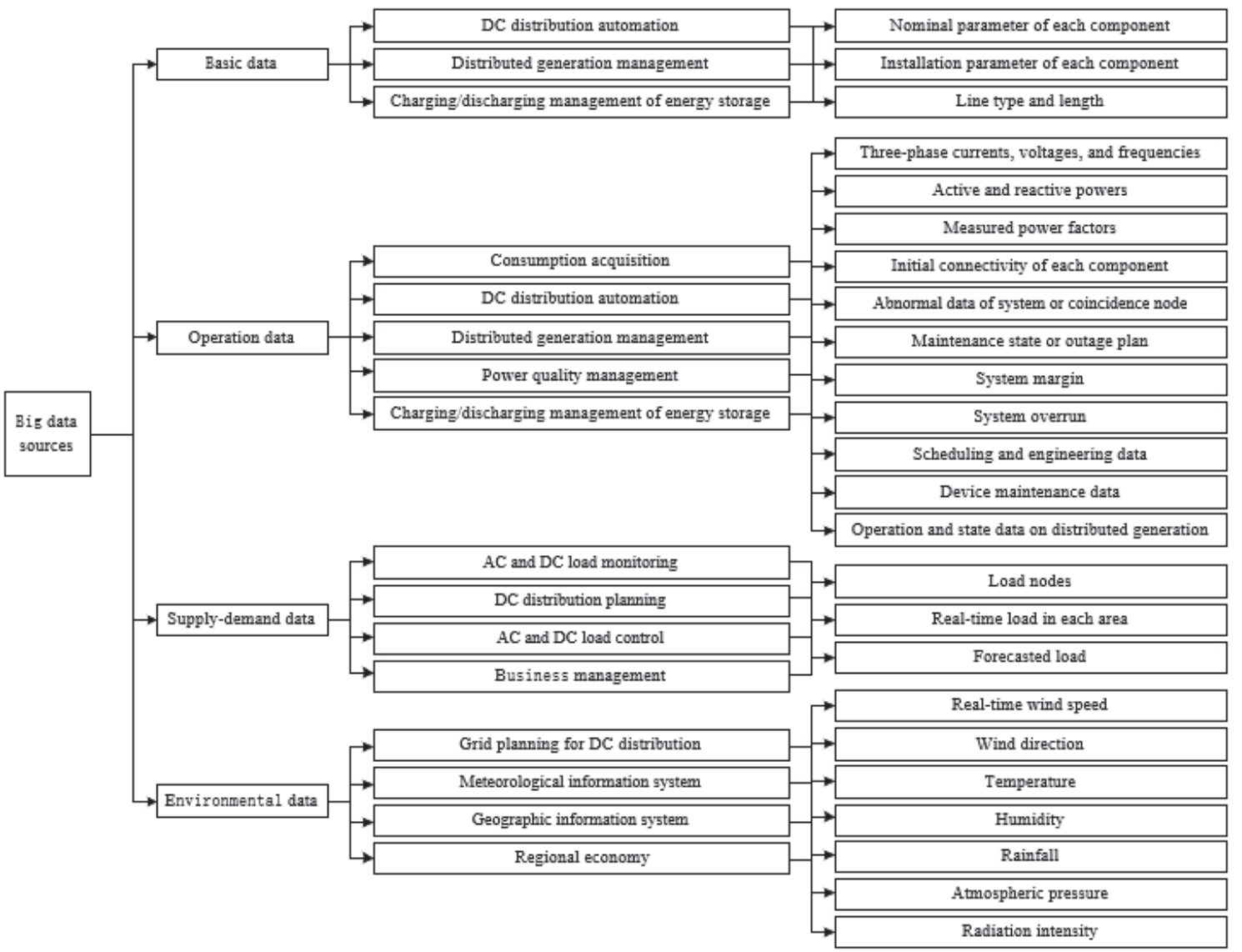

Figure 2 Sources of big data on system reliability 


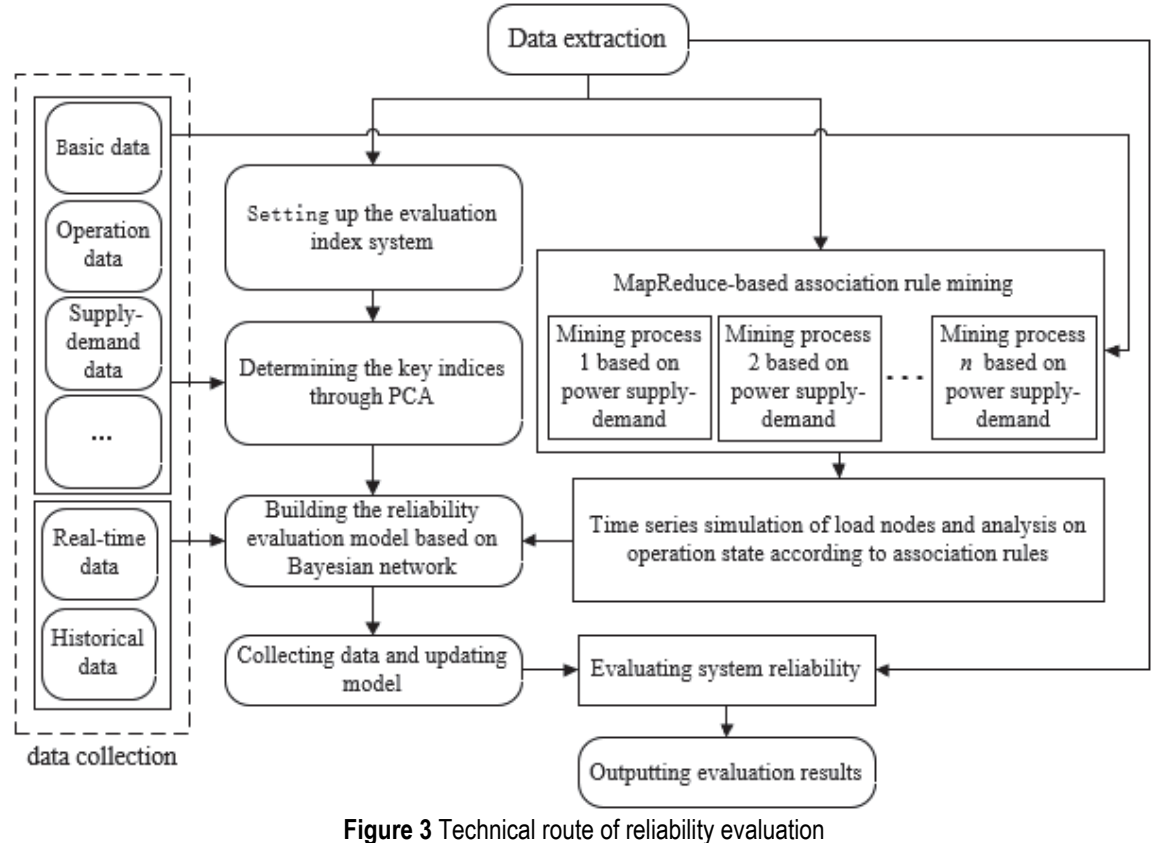

The DC distribution system for intelligent buildings is a DC bus-driven distributed supply and distribution system. Fig. 1 shows the structure of such a system with high power quality supply reliability. Specifically, the DC bus coordinates and control various distributed DC power sources, namely, PV generators, wind turbines, and batteries. Meanwhile, the bus transmits the rectified $\mathrm{AC} / \mathrm{DC}$ power to users on demand.

Focusing on the reliability of the DC distribution system for intelligent buildings, the massive amount of multi-source data on the system, which are collected by the scheduling and monitoring system, were divided into four categories: basic data, operation data, supply-demand data, and environmental data.

The sources of the big data on system reliability are presented in Fig. 2. The above data comes from the operation monitoring platform of intelligent building power companies and the data processing unit of intelligent building distribution system.

Fig. 3 shows the technical route of reliability evaluation for the DC distribution system in intelligent buildings in the context of big data.

\subsection{Construction of Evaluation Index System}

This paper aims to accurately evaluate the reliability of the DC distribution system for intelligent buildings in the context of big data. To realize this goal, it is important to assess the mean reliability of key components, devices, and the system under different load conditions on a monthly basis. Following the design principles of the system, this paper builds a comprehensive yet concise three-layer hierarchical system of both qualitative and quantitative indices. The indices belong to four levels: component level, node level, regional level, and system level.

Goal layer:

$R=\{$ Reliability of the DC distribution system for intelligent buildings $\}$.

Criteria layer:

$R=\{R 1, R 2, R 3, R 4\}=\{$ component level, node level, regional level, system level $\}$.
Alternative layer:

$R 1=\{R 11, R 12, R 13, R 14, R 15, R 16\}=$ safety probability of component current, safety margin of component current, out-of-limit probability of component current, out-of-limit expectation of component current, probability of load shedding induced by out-of-limit of component current, expectation of load shedding induced by out-of-limit of component current $\}$.

$R 2=\{R 21, R 22, R 23, R 24, R 25, R 26, R 27, R 28, R 29$, $R 210\}=\{$ safety probability of node voltage, upper limit of safety margin of node voltage, lower limit of safety margin of node voltage, out-of-limit probability of node voltage, expectation of node voltage violating upper limit, expectation of node voltage violating lower limit, probability of node load shedding, expectation of node power shortage, expectation of node power overload, availability of node power supply\}.

$R 3=\{R 31, R 32, R 33, R 34, R 35, R 36, R 37, R 38, R 39$, $R 310, R 311, R 312\}=$ safety margin of regional voltage, safety probability of regional voltage, safety margin of regional current, safety probability of regional current, outof-limit probability of regional current, out-of-limit expectation of regional current, out-of-limit probability of regional voltage, out-of-limit expectation of regional voltage, shedding probability of regional voltage, expectation of regional power shortage, expectation of regional power overload, availability of regional power supply $\}$.

$R 4=\{R 41, R 42, R 43, R 44, R 45, R 46, R 47, R 48, R 49$, $R 410, R 411, R 412\}=\{$ safety margin of system voltage, safety probability of system voltage, safety margin of system current, safety probability of system current, outof-limit probability of system current, out-of-limit expectation of system current, out-of-limit probability of system voltage, out-of-limit expectation of system voltage, shedding probability of system voltage, expectation of system power shortage, expectation of system power overload, availability of system power supply\}.

Based on the degree dimension, the above indices were divided into three groups: the margin indices reflecting the health or critical state of the system $(R 11, R 12, R 21, R 22$, 
$R 23, R 31, R 32, R 33, R 34, R 41, R 42, R 43$, and $R 44)$; outof-limit indices $(R 13, R 14, R 24, R 25, R 26, R 34, R 35, R 36$, $R 35, R 36, R 37$, and $R 38)$; load shedding indices $(R 15, R 16$, $R 27, R 28, R 29, R 210, R 39, R 310, R 311, R 312, R 49, R 410$, $R 411$, and $R 412$ ). The latter two groups jointly represent the risk state of the system.

The above indices were selected through overall consideration of the safety and energy efficiency of DC distribution system for intelligent buildings. The processing of index data is detailed in subsection 2.3.

Fig. 4 explains the evaluation process for system reliability.The output data of each sensor were extracted online and subjected to overrun detection. In this way, the operating state of intelligent building distribution system was recognized, and then the switching load was detected. Based on the historical operating data of massive elements, the margin indices were predicted according to the estimated operating state of the system.

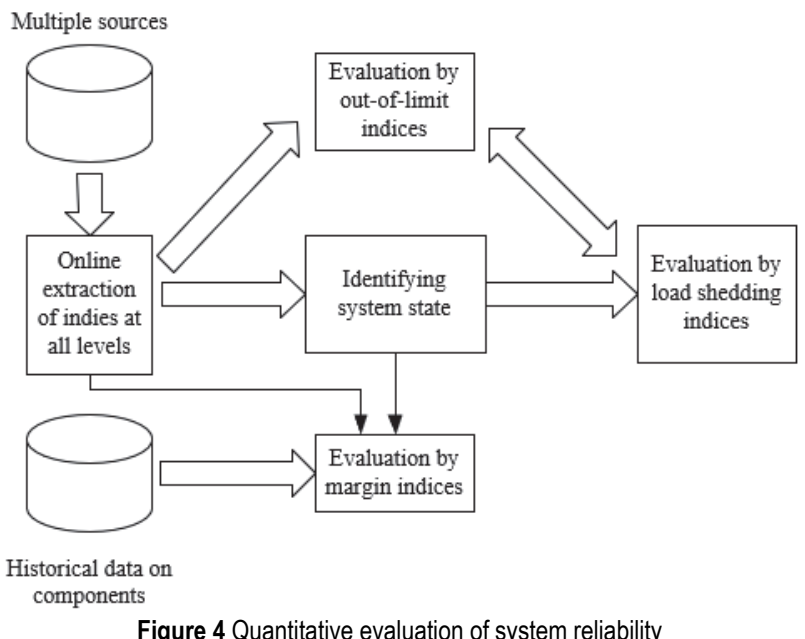

\subsection{PCA}

To eliminate the various redundant information, the PCA was performed on the above evaluation index system to remove the repetitive or strongly correlated indices:

Step 1. Normalization

To solve the multidimensionality of the indices, the data on every index was normalized by:

$$
N=(R-\bar{R}) / \varepsilon
$$

where, $R$ and $\varepsilon$ are the mean and standard deviation of the tertiary index, respectively.

Step 2. Construction of correlation matrix

Let $\operatorname{cov}\left(R_{i}, R_{j}\right)$ be the covariance between two tertiary indices. Then, the strength of the linear relationship between the two indices was measured by Pearson correlation coefficient:

$$
\rho_{i j}=\frac{\operatorname{cov}\left(R_{i}, R_{j}\right)}{\varepsilon\left(R_{i}\right) \varepsilon\left(R_{j}\right)}
$$

The correlation matrix $P$ of $m$ tertiary indices was established as:
$P=\left[\begin{array}{cccc}\rho_{11} & \rho_{12} & \cdots & \rho_{1 m} \\ \rho_{21} & \rho_{22} & \cdots & \rho_{2 m} \\ \vdots & \vdots & \vdots & \vdots \\ \rho_{m 1} & \rho_{m 2} & \cdots & \rho_{m m}\end{array}\right]$

Then, the eigenvalues $\lambda_{1}, \lambda_{2}, \ldots, \lambda_{n}$ and eigenvectors $v_{1}$, $v_{2}, \ldots, v_{m}$ were sorted in descending order by:

$|\lambda A-P|=0$

Step 3. Determination of principal components

The percentage of variance explained $(P V E)$ of the $k$ th index, denoted as $P V E_{k}$, was calculated by:

$P V E_{k}=\lambda_{k} / \sum_{l=1}^{m} \lambda_{l}$

Then, the cumulative percentage of variance explained (CPVE), denoted as $\sigma$, was calculated by:

$\sigma=\sum_{k=1}^{n} \lambda_{k} / \sum_{l=1}^{m} \lambda_{l}$

The minimum of $\sigma$ was determined according to the structural complexity of the DC distribution system structure for intelligent buildings. If the $\sigma$ value is greater than the minimum, $s_{p}$ will be determined as a principal component. Thus, the $\sigma$ value and its minimum jointly determine the number of principal components $P: S=\left\{s_{1}\right.$, $\left.s_{1}, \ldots, s_{P}\right\}$. The $P$ principal components carry most of the information in the $m$ tertiary indices.

Step 4. Determination of key indices

Let $L=\left[\rho\left(s_{p}, R_{i}\right)\right]$ be the load matrix of principal components, where $\rho\left(s_{i}, R_{i}\right) \in[-1,1]$ is the correlation coefficient between the $p$-th principal component $s_{p}$ and the $i$-th index $R_{i}$. The closer the $\rho\left(s_{i}, R_{i}\right)$ value is to -1 , the more negative is the correlation; the closer the value is to 1 , the more positive is the correlation.

During the evaluation of system reliability, there is no need to process all the data on the 40 tertiary indices. Referring to the load matrix $L$, the index $R_{i}$ corresponding to the maximum of $\left|\rho\left(s_{p}, R_{i}\right)\right|$ was selected as a key index.

\section{MAPREDUCE-BASED ASSOCIATION RULE MINING}

The operation reliability of the DC distribution system for intelligent buildings is affected by various factors. To build an accurate and fast reliability evaluation model, this paper introduces the improved Apriori algorithm in MapReduce under Hadoop framework. The operating mode and anomaly treatment are detailed as follows:

Firstly, the global frequent itemsets were mined from the original data on the indices of system reliability, the association rules were generated, and the support and confidence were calculated (See subsection 3.1 for details on this step). Next, the minimum support threshold and the minimum confidence threshold were defined according to the power and demand of the system, and the energy management strategy. Then, the association rules with 
support and confidence greater than or equal to the minimum thresholds were searched for, completing the parallel mining of association rules for the indices in the context of big data (See subsection 3.2 for details on this step).

\subsection{Traditional Apriori Algorithm}

Global frequent itemsets are prepared by joining and pruning frequent itemsets. The frequent itemset of $t-1$ can be expressed as $F_{t-1}=\left(f_{1}, f_{2}, \ldots, f_{P}\right)$. The two itemsets contained in $F_{t-1}$ can be defined as:

$\left\{\begin{array}{l}f_{i}=\left(f_{i-1}, f_{i-2}, \ldots, f_{i-(t-1)}\right) \\ f_{j}=\left(f_{j-1}, f_{j-2}, \ldots, f_{j-(t-1)}\right)\end{array}\right.$

The two itemsets could be automatically connected under the following condition:

$$
\left[f_{i-1}=f_{j-1}\right] \circ\left[f_{i-2}=f_{j-2}\right] \circ \cdots \circ\left[f_{i-(t-2)}=f_{j-(t-2)}\right]
$$

The connection between the two itemsets generates the $t$-th candidate set $C t$. If the $t$-1-th item subset of any sub itemset is not in the $t-1$-th frequent itemset $F_{t-1}$, then $C t$ is not a frequent itemset, and should be deleted to reduce the computing load.

\subsection{Association Rule Mining based on Supply and Demand}

To simplify the traversal of historical data on the indices and mine the association rules out of the multisource big data, this paper regards the influence of user supply and demand on system reliability as the impact on the historical data, and improved the Apriori algorithm. Below are the details about the association rule mining algorithm for reliability evaluation.

Firstly, association mining was carried out on the influence characteristics. Let characteristics $I C_{t-1}=\left(I C_{1}\right.$, $\left.I C_{2}, \ldots, I C_{P}\right)$ be the $\mathrm{t}-1$-th frequent itemset of the influence characteristics; $I C_{i}=\left(I C_{i 1}, I C_{i 2}, \ldots, I C_{i B}\right)$ be the influence characteristic set of the $\mathrm{i}$-th index; support and Confidence be the support threshold and confidence threshold, respectively. The hypothetical parameters were calculated as follows:

After traversing the dataset on the indices, the correlation matrix of the set User of A users on the influence characteristic set $I C_{i}$ was constructed as:

$$
\operatorname{REL}(i)=\left[\begin{array}{cccc}
\gamma_{i-11} & \gamma_{i-12} & \cdots & \gamma_{i-1 B} \\
\gamma_{i-21} & \gamma_{i-22} & \cdots & \gamma_{i-2 B} \\
\vdots & \vdots & \vdots & \vdots \\
\gamma_{i-A 1} & \gamma_{i-A 2} & \cdots & \gamma_{i-A B}
\end{array}\right]
$$

During the traversal of the dataset, if the supply and demand of the $a$-th user appears in the data on the $b$-th index, then the value in row $a$ and column $b$ of the correlation matrix equals 1 ; otherwise, it equals 0 . The support of the $b$-th influence characteristic, $I C_{i b}$, was calculated by adding up column $b$ of matrix $R E L(i)$ :
$\operatorname{support}\left(I C_{i b}\right)=\frac{\sum \mathrm{Num}_{b}}{A} \dot{c}$

where, $\Sigma \mathrm{Num}_{b}$ is the sum of the support of $I C_{i b}$. Then, the columns smaller than support were removed from the matrix, producing a frequent itemset $F_{1}$. The candidate itemset $C_{2}$ could be automatically connected by $F_{1}$. The corresponding support was calculated by:

$\operatorname{support}\left(I C_{i b} \rightarrow I C_{i c}\right)=\frac{\sum_{r=1}^{A}\left(\mathrm{Num}_{r b} \circ \mathrm{Num}_{r c}\right)}{A}$

where, ${ }^{\circ}$ is the operator of the number of associations between $I C_{i b}$ and $I C_{i c}$. Next, the columns smaller than support were removed from the candidate itemset $C_{2}$ to obtain the frequent itemset $F_{2}$ of the two itemsets. If $t>3$, the frequent itemset $F_{t-1}$ is self-connected to the candidate itemset $C_{t}$. The corresponding support was calculated by:

$$
\begin{aligned}
& \operatorname{support}\left(I C_{i b} \rightarrow I C_{i c} \rightarrow \ldots I C_{i B}\right) \\
& =\frac{\sum_{r=1}^{A}\left(\operatorname{Num}_{r b} \circ \operatorname{Num}_{r c} \circ \ldots \circ \mathrm{Num}_{i B}\right)}{A}
\end{aligned}
$$

Through iterative updating, the $t$-item frequent itemset $I C_{t}$ was obtained by:

$$
I C_{t}=\left\{\varepsilon \in C_{t-1} \mid \operatorname{support}(\varepsilon) \geq \operatorname{support}\right\}
$$

Through the self-connection by $I C_{t}$, the candidate itemset $C_{t+1}$ could be obtained. If $C_{t+1}$ is not an empty set, the frequent itemsets $I C_{t-1}$ should be reconnected; if $C_{t+1}$ is an empty set, it is necessary to judge the confidence matrix Confidence $(i)$, which stores the confidence between the characteristics in the influence characteristic set $I C_{t}$.

After initializing Confidence $(i)$, the confidence of each frequent attribute of the $t$-item frequent itemset $I C_{t}$ was calculated by:

$$
\operatorname{confidence}\left(I C_{i b} \rightarrow I C_{i c}\right)=\frac{\sum_{r=1}^{A}\left(\mathrm{Num}_{r b} \circ \mathrm{Num}_{r c}\right)}{\sum_{r=1}^{A}\left(\mathrm{Num}_{r b}\right)}
$$

If it is greater than the confidence threshold, Confidence $(i)$ was updated, and the corresponding association rules were outputted.

According to the association rules and confidence matrix, the correlations of uncorrelated indices were predicted and rated by the following steps:

Step 1. By traversing the data on the indices, the authors set up the user supply-demand matrix $P M(i)$, index score matrix $T S M(i)$, and influence characteristic score matrix $\operatorname{ICM}(i)$ : 


$$
P M(i)=\left[\begin{array}{cccc}
\eta_{i-11} & \eta_{i-12} & \cdots & \eta_{i-1 B} \\
\eta_{i-21} & \eta_{i-22} & \cdots & \eta_{i-2 B} \\
\vdots & \vdots & \vdots & \vdots \\
\eta_{i-A 1} & \eta_{i-A 2} & \cdots & \eta_{i-A B}
\end{array}\right]
$$

where, $A$ is the number of user supply-demand items; $B$ is the number of influence characteristics in $I C_{i} ; \eta_{i-a b}$ is the influence characteristic $I C_{i b}$ in $I C_{i}$ embodied in item $a$ (if $\eta_{i-a b}=1$, item $a$ contains impact characteristic $I C_{i b}$; if $\eta_{i-a b}$ $=0$, item $a$ does not contain impact characteristic $\left.I C_{i b}\right)$. The index scores on multiple supply-demand items were summarized to obtain the index score matrix $\operatorname{TSM}(i)$ :

$$
\operatorname{TSM}(i)=\left[\begin{array}{cccc}
\xi_{i-11} & \xi_{i-12} & \cdots & \xi_{i-1 C} \\
\xi_{i-21} & \xi_{i-22} & \cdots & \xi_{i-2 C} \\
\vdots & \vdots & \vdots & \vdots \\
\xi_{i-B 1} & \xi_{i-B 2} & \cdots & \xi_{i-B C}
\end{array}\right]
$$

where, $C$ is the number of indices; $\xi_{i-b c}$ is the cumulative value of impact characteristic $I C_{i b}$ on index $c$ (if $\xi_{i-b c}=1$, index $c$ has the cumulative score of $I C_{i b}$; if $\xi_{i-b c}=0$, index $c$ does not have the cumulative score of $\left.I C_{i b}\right)$. The influence characteristic score matrix $I C M(i)$ was established as:

$$
\operatorname{ICM}(i)=\left[\begin{array}{cccc}
\delta_{i-11} & \delta_{i-12} & \cdots & \delta_{i-1 C} \\
\delta_{i-21} & \delta_{i-22} & \cdots & \delta_{i-2 C} \\
\vdots & \vdots & \vdots & \vdots \\
\delta_{i-A 1} & \delta_{i-A 2} & \cdots & \delta_{i-A C}
\end{array}\right]
$$

where, each column vector is the cumulative score of impact characteristic $I C_{i b}$ on index $c$; each row vector is the cumulative score of all supply-demand items on $I C_{i b}$.

Step 2. Based on TSM(i) and Confidence $(i)$, the score of index $c$ on impact characteristic $I C_{i b}$ was predicted by:

$$
p s(i)=\max \left(\xi_{i-b c}\right) \times \operatorname{Confidence}(i)
$$

All the predicted scores $P S(i)$ were combined into a predicted score matrix ps $(i)$. By traversing $P S(i)$ and replacing the zeros with the corresponding values of $\operatorname{TSM}(i)$, the final predicted score matrix $P S^{*}(i)$ was established for the influence characteristics of reliability evaluation.

Step 3. Let $\mu_{i}$ be the coefficient of a supply-demand item. Then, a predicted score matrix $P R(i)$ was established for the influence of related items on reliability evaluation:

$$
P R(i)=\sum_{i=s}^{C} \mu_{i} \cdot P M(i)_{A \times B} \cdot \operatorname{TSM}(i)_{B \times S}, \sum_{i=S}^{C} \mu_{i}=1
$$

The final predicted score matrix $P R^{*}(i)$ was obtained by traversing $P R(i)$ and replacing the zeros with the corresponding values of $I S M(i)$.

\section{CONSTRUCTION OF RELIABILITY EVALUATION MODEL}

\subsection{Logical Relationship in Bayesian Network}

According to the technical route in Section 2, the nodes of Bayesian network for reliability evaluation were divided into five categories: (1) component level nodes for distribution components like transformers, converters, power lines, and disconnectors; (2) joint nodes about the effect of disconnectors and power lines; (3) virtual nodes (indirect nodes) that simplifies the calculation; (4) regional level nodes reflecting user load; (5) a system level node representing the DC distribution system. The joint and virtual nodes were both regarded as elements on the node layer. Thus, the network nodes correspond to the four levels of the indices: component level, node level, regional level, and system level.

Referring to the association rules of the influence of supply-demand items on reliability characteristics, the relationship between network nodes on adjacent levels was categorized into four classes: and, or, joint, and causal. As shown in Tab. 1, the logical relationship between component node and virtual node is and / or; that between joint nodes is joint; that between joint node, virtual node, and regional node is and / or; that between regional node and system node is causal. Note that $p$ stands for the failure probability of joint nodes $X$ and $Y$ (its value equals the ratio of the opening time of disconnector to line repair time, in the event of line fault); $n_{X}$ and $n_{Y}$ are the number of users corresponding to nodes $X$ and $Y 2$, respectively. The failure probability of the distribution system could be one of the four values: $0, n_{Y} /\left(n_{X}+n_{Y}\right), n_{X} /\left(n_{X}+n_{Y}\right)$ and 1 .

Table 1 Logical relationship between nodes in Bayesian network

\begin{tabular}{|c|c|c|c|}
\hline Logical relationship & $A$ & $B$ & Failure probability \\
\hline \multirow{4}{*}{ and } & 0 & 0 & 0 \\
\cline { 2 - 4 } & 0 & 1 & 0 \\
\cline { 2 - 4 } & 1 & 0 & 0 \\
\cline { 2 - 4 } & 1 & 1 & 1 \\
\hline \multirow{4}{*}{ or } & 0 & 0 & 0 \\
\cline { 2 - 4 } & 0 & 1 & 1 \\
\cline { 2 - 4 } & 1 & 0 & 1 \\
\cline { 2 - 4 } & 1 & 1 & 1 \\
\hline \multirow{3}{*}{ joint } & 0 & 0 & 0 \\
\cline { 2 - 4 } & 1 & 0 & $p$ \\
\hline \multirow{3}{*}{ causal } & 0 & 0 & $n_{Y} /\left(n_{X}+n_{Y}\right)$ \\
\cline { 2 - 4 } & 0 & 1 & $n_{X} /\left(n_{X}+n_{Y}\right)$ \\
\cline { 2 - 4 } & 1 & 0 & 1 \\
\cline { 2 - 4 } & 1 & 1 & \\
\hline \multirow{3}{*}{} & & & 1 \\
\hline
\end{tabular}

\subsection{Reliability Modeling of Key Devices}

(1) Modular multilevel high-frequency DC transformer (MDCT)

To control the stress on low-voltage components, the MDCT is widely adopted in the DC distribution system for intelligent buildings, which reduces the number of power modules. The MDCT mainly consists of four modular multi-level converter (MMC) bridge arms, an internal and external valve cooling system, an AC/DC module, a highfrequency transformer, and a protection and control system. The reliability of the MDCT can be calculated by: 


$$
\begin{aligned}
& R_{\mathrm{MDCT}}(t)=\left[R_{\mathrm{MMC}}(t)\right]^{4} \times R_{\mathrm{VCS}}(t) \times R_{\mathrm{AC} / \mathrm{DC}}(t) \times \\
& \times R_{\mathrm{HFT}}(t) \times R_{\mathrm{C} \& \mathrm{P}}(t)=\left[R_{\mathrm{HBM}}(t) \times R_{\mathrm{L}}(t)\right]^{4} \times R_{\mathrm{VICS}}(t) \times \\
& \times R_{\mathrm{VOCS}}(t) \times\left[R_{\mathrm{IGBT}}(t)\right]^{4} \times R_{\mathrm{C}}(t) \times R_{\mathrm{HFT}}(t) \times R_{\mathrm{C} \& \mathrm{P}}(t)
\end{aligned}
$$

where, $R_{\mathrm{MMC}}(t), R_{\mathrm{VCS}}(t), R_{\mathrm{AC} / \mathrm{DC}}(t), R_{\mathrm{HFT}}(t)$, and $R_{\mathrm{C} \& \mathrm{P}}(t)$ are the reliabilities of the MMC bridge arm, valve cooling system, AC//DC conversion module, high-frequency transformer, and protection and control system, respectively; $R_{\mathrm{HBM}}(t)$, and $R_{\mathrm{L}}(t)$ are the reliabilities of halfbridge module (HBM) and reactor $\mathrm{L}$ of the MMC bridge arm, respectively; $R_{\mathrm{VICS}}(t)$ and $R_{\mathrm{VOCS}}(t)$ are the reliabilities of internal and external cooling systems, respectively; $R_{\mathrm{IGBT}}(t)$ and $R_{\mathrm{C}}(t)$ are the reliabilities of the insulated-gate bipolar transistor (IGBT) and filter capacitor $C$ in the $\mathrm{AC} / \mathrm{DC}$ module, respectively. Considering the active standby design, the failure rate of the MDCT can be expressed as:

$$
\begin{aligned}
& f_{\mathrm{MDCT}}=4 \times f_{\mathrm{MMC}}+f_{\mathrm{VCS}}+ \\
& +f_{\mathrm{AC} / \mathrm{DC}}+f_{\mathrm{HFT}}+f_{\mathrm{C} \& \mathrm{P}} \\
& =\left[\begin{array}{l}
4 \times\left(\frac{2 \times f_{\mathrm{IGBT}}+f_{\mathrm{C}}+f_{\mathrm{PSF}}}{\sum_{i=k_{\mathrm{HBM}}}^{R} \frac{1}{i}}+f_{\mathrm{L}}\right. \\
+f_{\mathrm{VICS}}+f_{\mathrm{VOCS}}
\end{array}\right]+ \\
& +\frac{4 \times f_{\mathrm{IGBT}}+f_{\mathrm{C}}}{\sum_{i=k_{\mathrm{AC} / \mathrm{DC}}}^{S} \frac{1}{i}}+\frac{f_{\mathrm{HFT}}}{\sum_{i=k_{\mathrm{T}}}^{T} \frac{1}{i}}+f_{\mathrm{C \& P}}
\end{aligned}
$$

where, $f_{\mathrm{MMC}}(t), f_{\mathrm{VCS}}(t), f_{\mathrm{AC} / \mathrm{DC}}(t), f_{\mathrm{HFT}}(t), f_{\mathrm{C} \& \mathrm{P}}(t), f_{\mathrm{VICS}}(t)$, and $f_{\text {Vocs }}(t)$ are the failure rates of the MMC bridge arm, valve cooling system, AC//DC conversion module, highfrequency transformer, and protection and control system, respectively; $f_{\mathrm{IGBT}}(t)$ and $f_{\mathrm{C}}(t)$ are the failure rates of the IGBT module and filter capacitor $C$ in the HBM or AC/DC module, respectively; $f_{\mathrm{PSF}}(t)$ is the failure rate of power supply. Tab. 2 shows the failure rate of each component in the MDCT.

(2) DC circuit breaker

So far, there is no engineering application of DC circuit breaker in medium voltage DC distribution systems. This paper selects the hybrid DC circuit breaker (HDCB), which combines the strengths of mechanical and all solid state DC circuit breakers, for reliability modeling. The failure rate of active standby design can be described by:

$$
\begin{aligned}
& f_{\mathrm{HDCB}}=\frac{\left(f_{\mathrm{IGBT}}+f_{\mathrm{C}}+f_{\mathrm{R}}+f_{\mathrm{VD}}\right)}{\sum_{i=k_{\mathrm{LE}}}^{U} \frac{1}{i}}+ \\
& +f_{\mathrm{LA}} \times n_{\mathrm{LA}}+f_{\mathrm{MS}}+f_{\mathrm{C} \& \mathrm{P}}
\end{aligned}
$$

where, $f_{\mathrm{R}}$ and $f_{\mathrm{VD}}$ are the failure rates of resistors and diodes, respectively; $f_{\mathrm{LA}} \times n_{\mathrm{LA}}$ is the failure rate of $n_{\mathrm{LA}}$ arresters; $f_{\mathrm{MS}}$ is the failure rate of mechanical switches.
Tab. 3 shows the failure rate of each component in the HDCB.

Table 2 Failure rate of each component in the MDCT

\begin{tabular}{|} 
Table 2 Failure rate of each component in the MDCT \\
\begin{tabular}{|c|c|c|c|}
\hline \multicolumn{2}{|c|}{ Components } & $\begin{array}{c}\text { Failure rate } \\
\text { (times / year) }\end{array}$ & $\begin{array}{c}\text { Element } \\
\text { factor }\end{array}$ \\
\hline \multirow{3}{*}{ HBM } & IGBT & 0.001546 & 2 \\
\cline { 2 - 4 } & $\mathrm{C}$ & 0.001271 & 1 \\
\cline { 2 - 4 } Valve cooling \\
system
\end{tabular} & $\begin{array}{c}\text { Internal cooling } \\
\text { system }\end{array}$ & 0.008416 & 1 \\
\cline { 2 - 4 } & $\begin{array}{c}\text { External cooling } \\
\text { system }\end{array}$ & 0.02109 & 1 \\
\hline \multirow{2}{*}{ AC/DC module } & IGBT & 0.0098473 & 1 \\
\cline { 2 - 4 } & $\mathrm{C}$ & 0.000512 & 1 \\
\hline \multicolumn{2}{|c|}{ High-frequency transformer } & 0.002412 & 1 \\
\hline \multicolumn{2}{|c|}{ Protection and control system } & 0.412568 & 1 \\
\hline
\end{tabular}

Table 3 Failure rate of each component in the HDCB

\begin{tabular}{|c|c|c|}
\hline Components & $\begin{array}{c}\text { Failure rate } \\
\text { (times / year) }\end{array}$ & Element factor \\
\hline IGBT & 0.004125 & 1 \\
\hline $\mathrm{C}$ & 0.005218 & 1 \\
\hline $\mathrm{R}$ & 0.000623 & 1 \\
\hline Diode & 0.001458 & 1 \\
\hline Arrester & 0.001873 & $n_{\mathrm{LA}}$ \\
\hline Mechanical switch & 0.004711 & 1 \\
\hline Protection and control system & 0.126477 & 1 \\
\hline
\end{tabular}

(3) Converter station

The reliability parameters of the conventional line commutate converter (LCC) can be obtained from the statistics of International Council on Large Electric Systems (CIGRE). In this paper, the emerging voltage source converter (VSC) is selected for reliability modeling. The converter station is mainly composed of an AC system and auxiliary devices, a converter valve, a DC device, and a protection and control system. The failure rate of the converter station with active standby design can be calculated by:

$$
\begin{aligned}
& f_{\mathrm{IV}}=6 \times f_{\mathrm{HBM}}+f_{\mathrm{VICS}}+f_{\mathrm{VOCS}}+f_{\mathrm{C} \& \mathrm{P}} \\
& =\left[\begin{array}{l}
6 \times\left[\begin{array}{l}
\frac{2 \times f_{\mathrm{IGBT}}+f_{\mathrm{C}}+f_{\mathrm{PSF}}}{\sum_{i=k_{\mathrm{HBM}}}^{R} \frac{1}{i}}+f_{\mathrm{L}} \\
+f_{\mathrm{VICS}}+f_{\mathrm{VOCS}}
\end{array}\right]
\end{array}\right]+f_{\mathrm{C \& P}}
\end{aligned}
$$

For the AC system and auxiliary devices, DC device, and protection and control system, the corresponding reliability parameters can be determined by quantifying the difference between LCC and VSC converters:

$$
f_{\mathrm{VSC}}=f_{\mathrm{LCC}} \prod_{i-1}^{V} \frac{1-0.242 \lambda_{\mathrm{VSC}-i}}{1-0.242 \lambda_{\mathrm{LCC}-i}}
$$

where, $f_{\mathrm{LCC}}$ and $f_{\mathrm{VSC}}$ are the failure rates of the corresponding components of LCC and VSC converter stations, respectively; $\lambda_{\mathrm{LCC}-i}$ and $\lambda_{\mathrm{VSC}-i}$ are the influence degree of the $i$-th element in the reliability model of the corresponding component on the failure rate of the component. Tab. 4 shows the failure rate of each component in the VSC converter station. 
Table 4 Failure rate of each component in the VSC converter station

\begin{tabular}{|c|c|c|}
\hline Component & $\begin{array}{c}\text { Failure rate } \\
\text { (times / year) }\end{array}$ & Failure duration / h \\
\hline AC system and auxiliary devices & 0.3216 & 8.8566 \\
\hline Converter valve & 2.5411 & 18.451 \\
\hline DC device & 0.9470 & 1.9841 \\
\hline Protection and control system & 1.2433 & 2.5936 \\
\hline
\end{tabular}

(4) Wind generation system and PV system

Distributed generation systems generally have a complex structure of multiple components. The failure rate of any component could affect the failure rate of the entire system. This paper models the reliability of a wind generation system, which can be connected to the lowvoltage DC bus of intelligent buildings. The system encompasses wind turbine, AC/DC module, rack cable, DC circuit breaker, and DC bus. Based on the two system states (fault shutdown vs. normal operation), the system was split into two subsystems: generator-rack cable$\mathrm{AC} / \mathrm{DC}$ circuit breaker, and DC bus. The former represents the fault of generator outage, and the latter, the fault of system outage. Then, the system failure rate can be expressed by:

$$
\begin{aligned}
& f_{\mathrm{WP}}=f_{\mathrm{WPS} 1}+f_{\mathrm{WPS} 2} \\
& =\left(f_{\mathrm{WT}}+f_{\mathrm{AC} / \mathrm{DC}}+f_{\mathrm{RC}}+f_{\mathrm{HDCB}}\right)+\left(f_{\mathrm{CB}}\right)
\end{aligned}
$$

where, $f_{\mathrm{WPS} 1}$ and $f_{\mathrm{WPS} 2}$ are the failure rates of the two subsystems, respectively; $f_{\mathrm{WT}}, f_{\mathrm{RC}}$, and $f_{\mathrm{CB}}$ are the failure rates of wind turbine, rack cable, and DC bus, respectively. Let $t_{\mathrm{WT}}, t_{\mathrm{AC} / \mathrm{DC}}, t_{\mathrm{RC}}, t_{\mathrm{HDCB}}$, and $t_{\mathrm{CB}}$ be the mean outage durations of wind turbine, DC/DC module, rack cable, DC circuit breaker, and DC bus, respectively. Then, the annual mean failure duration of the wind generation system can be expressed by:

$$
\begin{aligned}
& t_{\mathrm{WP}}=t_{\mathrm{S} 1}+t_{\mathrm{S} 2} \\
& f_{\mathrm{WT}} t_{\mathrm{WT}}+f_{\mathrm{AC} / \mathrm{DC}} t_{\mathrm{AC} / \mathrm{DC}} \\
& =\frac{+f_{\mathrm{RC}} t_{\mathrm{RC}}+f_{\mathrm{HDCB}} t_{\mathrm{HDCB}}}{f_{\mathrm{WT}}+f_{\mathrm{AC} / \mathrm{DC}}+f_{\mathrm{RC}}+f_{\mathrm{HDCB}}}+ \\
& +\frac{f_{\mathrm{CB}} t_{\mathrm{CB}}}{f_{\mathrm{CB}}}
\end{aligned}
$$

Similarly, the PV system was divided into four subsystems: PV module-DC bus-anti-counter current diode, DC output circuit breaker-DC input circuit breakeranti-counter current diode, AC/DC module-DC circuit breaker, and DC bus. The four subsystems characterize the failure rates of one PV module, a group of PV modules, several groups of PV modules, and the PV system, respectively. Then, the system reliability can be expressed by:

$$
\begin{aligned}
& f_{\mathrm{PP}}=f_{\mathrm{PPS} 1}+f_{\mathrm{PPS} 2}+f_{\mathrm{PPS} 3}+f_{\mathrm{PPS} 4} \\
& =\left(n_{\mathrm{PM}} f_{\mathrm{PM}}+f_{\mathrm{DF}}+f_{\mathrm{VD}}\right)+\left(2 f_{\mathrm{HDCB}}+f_{\mathrm{VD}}\right)+ \\
& +\left(f_{\mathrm{DC} / \mathrm{DC}}+f_{\mathrm{HDCB}}\right)+f_{\mathrm{CB}}
\end{aligned}
$$

where, $f_{\mathrm{PPS} 1}, f_{\mathrm{PPS} 2}, f_{\mathrm{PPS} 3}$, and $f_{\mathrm{PPS} 4}$ are the failure rates of the four subsystems, respectively; $f_{\mathrm{PM}}, f_{\mathrm{DF}}$, and $f_{\mathrm{DC} / \mathrm{DC}}$ are the failure rates of the PV module, DC bus, and DC/DC module, respectively; $n_{\mathrm{PM}}$ is the number of PV panels in a $\mathrm{PV}$ module. Let $t_{\mathrm{PM}}, t_{\mathrm{DF}}, t_{\mathrm{VD}}$, and $t_{\mathrm{DC} / \mathrm{DC}}$ be the mean outage time of PV module, DC bus, anti-counter current diode, and DC/DC module, respectively. Then, the annual mean failure duration of the PV system can be expressed by:

$$
\begin{aligned}
& t_{\mathrm{PP}}=t_{\mathrm{PPS} 1}+t_{\mathrm{PPS} 2}+t_{\mathrm{PPS} 3}+t_{\mathrm{PPS} 4}= \\
& =\frac{n_{\mathrm{PM}} f_{\mathrm{PM}} t_{\mathrm{PM}}+f_{\mathrm{DF}} t_{\mathrm{DF}}+f_{\mathrm{VD}} t_{\mathrm{VD}}}{n_{\mathrm{PM}} f_{\mathrm{PM}}+f_{\mathrm{DF}}+f_{\mathrm{VD}}}+ \\
& +\frac{2 f_{\mathrm{HDCB}} t_{\mathrm{HDCB}}+f_{\mathrm{VD}} t_{\mathrm{VD}}}{2 f_{\mathrm{HDCB}}+f_{\mathrm{VD}}}+ \\
& +\frac{f_{\mathrm{DC} / \mathrm{DC}} t_{\mathrm{DC} / \mathrm{DC}}+f_{\mathrm{HDCB}} t_{\mathrm{HDCB}}}{f_{\mathrm{DC} / \mathrm{DC}}+f_{\mathrm{HDCB}}}+\frac{f_{\mathrm{CB}} t_{\mathrm{CB}}}{f_{\mathrm{CB}}}
\end{aligned}
$$

(5) Energy storage

The energy produced by distributed generation systems is highly intermittent, stochastic, and volatile. The DC distribution system for intelligent buildings covers wind power generation system, PV system, and energy storage. Among them, the energy storage system is critical to the smoothing of voltage and current. Here, the reliability of the large capacity, durable lithium titanate battery is denoted by $f_{\text {soc }}$.

\subsection{System Reliability Evaluation based on Bayesian Network}

The supply-demand curve of the DC distribution system for intelligent buildings changes constantly from time to time. Considering the failure series of the system, the system operation in a year was divided into $Q$ periods. It was assumed that the state of each component remains constant in each period, and the durations of failure state and normal state of each component obey exponential distribution. The mean failure duration and mean normal duration of each component were taken as the minimum durations of the two states, $T_{\mathrm{F}-\min }$ and $T_{\mathrm{O}-\min }$, respectively. Within $T_{\mathrm{F}-\text { min }}$ and $T_{\mathrm{O}-\mathrm{min}}$, whether a node on a level of the distribution system fails or works normally depends on its logical relationship with other associated nodes, that is, the association rules about the influence of user supplydemand on reliability. On this basis, the parallel operation of distributed generation and $\mathrm{AC}$ grid was adopted to evaluate the reliability of the distribution network with distributed generation:

Step 1. Initialize the reliability parameters, energy storage parameters, historical wind speed, historical radiation intensity, building load, and other data of the DC distribution system. Set the simulation interval to $1 \mathrm{~h}$, the system confidence probability to 0.95 , and the calculation accuracy to $10^{-6}$.

Step 2. Compute the power outputted by wind generation system $\left(P_{\mathrm{WP}}\right)$ and $\mathrm{PV}$ system $\left(P_{\mathrm{PP}}\right)$, according to the historical data on wind speed and radiation intensity, and calculate the total power produced by distributed generation: $\sum P=P_{\mathrm{WP}}+P_{\mathrm{PP}}$. Then, simulate the time series of distributed generation, and deduce the ratio of distributed generation in annual power generation from the grid supply. After that, sample the data from all components of the system, and establish a time series of long-year operation state. 


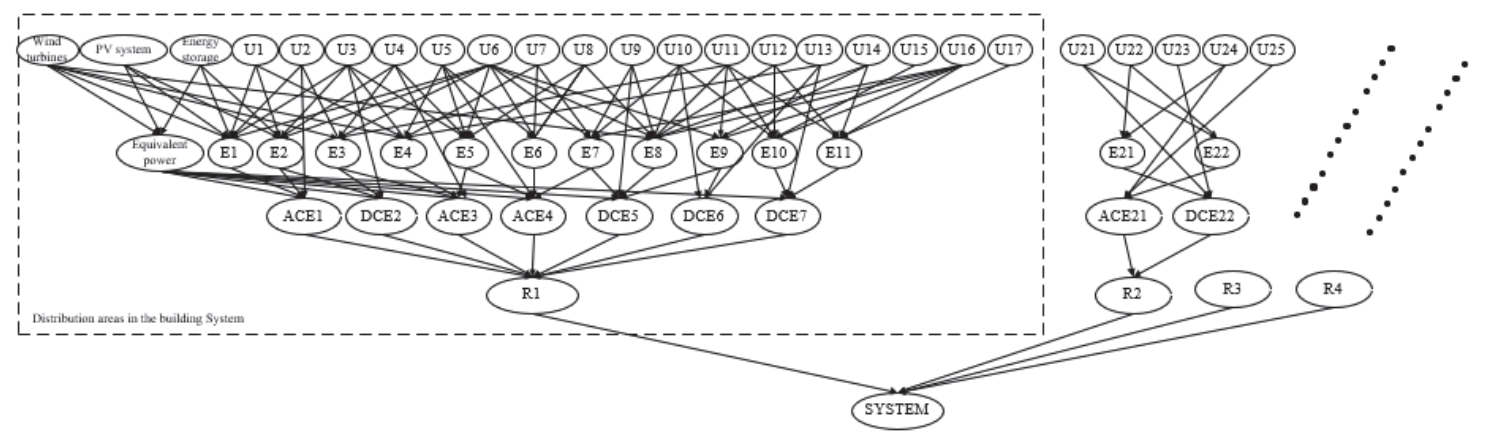

Figure 5 Bayesian network of the DC distribution system for intelligent buildings

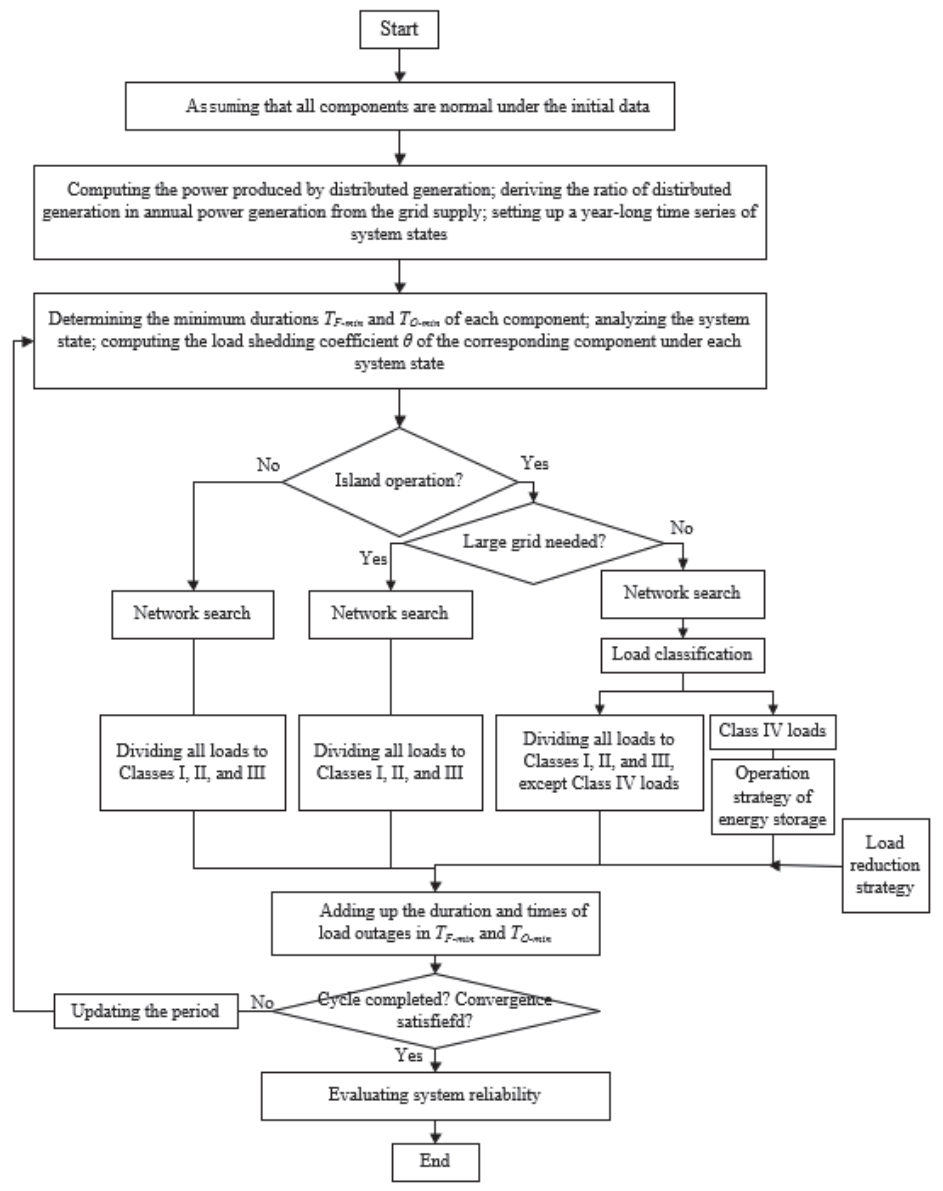

Figure 6 Flow chart of system reliability evaluation based on Bayesian network

Step 3. Perform time series simulation to analyze each load node, according to the association rules reflecting the influence of user supply-demand on reliability, i.e., and, or, joint, and causal, within $T_{\mathrm{F}-\min }$ and $T_{\mathrm{O}-\mathrm{min}}$, thereby determining the minimum $T_{\mathrm{F}-\text { min }}$ and $T_{\mathrm{O} \text {-min }}$ for each component.

Step 4. Analyze the system state based on the fault rate of each component, and calculate the load shedding coefficient $\theta$ of the corresponding component under each system state. The $\theta$ value falls in $[0,1]$. If $\theta=1$ or 0 , the system is normal or failed; if $0<\theta<1$, the $\theta$ value reflects the load shedding induced by the failure of different components in the system.

Step 5. Judge whether there is island operation in the DC distribution system for intelligent buildings, i.e., the load node is connected with the distributed generation or energy storage, rather than the $\mathrm{AC}$ grid. If the island operation does not exist, classify all user loads under each system state based on their supply-demand situation:
Class I: a load that operates normally, without being affected by fault component or device.

Class II: a load whose supply can be restored via power transmission.

Class III: a load whose supply cannot be restored.

Next, count the power grain/loss states of various loads, and adds up the duration and times of outages within $T_{\mathrm{F}-\min }$ and $T_{\mathrm{O}-\mathrm{min}}$.

If the island operation exists, divide all user loads into four types: Classes I-III are the same as above; Class IV refers to any load only powered by distributed generation. Then, analyze Class IV loads by the following strategies of energy storage and load shedding:

(a) If the total power produced by distributed generation surpasses the power demand of the users, judge whether the energy storage is saturated in the current period. If yes, do not charge the energy storage system; otherwise, charge the system.

(b) If the total power produced by distributed generation falls short of the power demand of the users, 
judge whether energy storage reaches the minimum in the current period. If yes, do not discharge the system; otherwise, discharge the system.

Since the discharge power of energy storage system cannot exceed the maximum discharge power, if the discharge power exceeds the maximum level, control it to the maximum level. In addition, the discharge of distributed generation and energy storage is not enough to meet the power demand of all users. Therefore, implement the load shedding strategy. If the discharge power lies below the maximum level, analyze the power gain/loss states of various loads according to the logical relationship, provided that the discharge time of energy storage is greater than $2 \mathrm{~min}$; implement load shedding, provided that the discharge time is not greater than $2 \mathrm{~min}$.

Step 6. Using the Bayesian network in Fig. 5, determine the state and duration of each load node in $T_{\mathrm{F}-\mathrm{min}}$ and $T_{\mathrm{O}-\mathrm{min}}$.

Step 7. Judge whether the number of cycles reaches the preset value. If not, return to Step 3. Add up the parameters, such as failure duration of the system and the number of outage users, to obtain the reliability of the system during the simulation, i.e., the ratio of the failure duration to the simulation period.

Step 8. Judge whether the convergence criterion is satisfied. If yes, update the period to evaluate the reliability of the distribution system in the new period. Otherwise, return to Step 3.

Fig. 6 provides the chart of system reliability evaluation based on Bayesian network.

\section{EXPERIMENTS AND RESULTS ANALYSIS}

To verify the effectiveness of our model, this paper selects the DC distribution system for intelligent buildings in an industrial park, Shenzhen, southern China, as an example. The original data on the evaluation indices were sampled at an interval of $15 \mathrm{~min}$. In total, the collected data amounted to $1.23 \mathrm{G}$. Overall, there were 40 indices, including 6 on the component level, 10 on the node level, 12 on the regional level, and 12 on the system level. To obtain the difference between index data, the CPVEs of core indices were counted. By Eqs. (5) and (6), the PVE and CPVE of each index were calculated. The calculation results are partly presented in Tab. 5 .

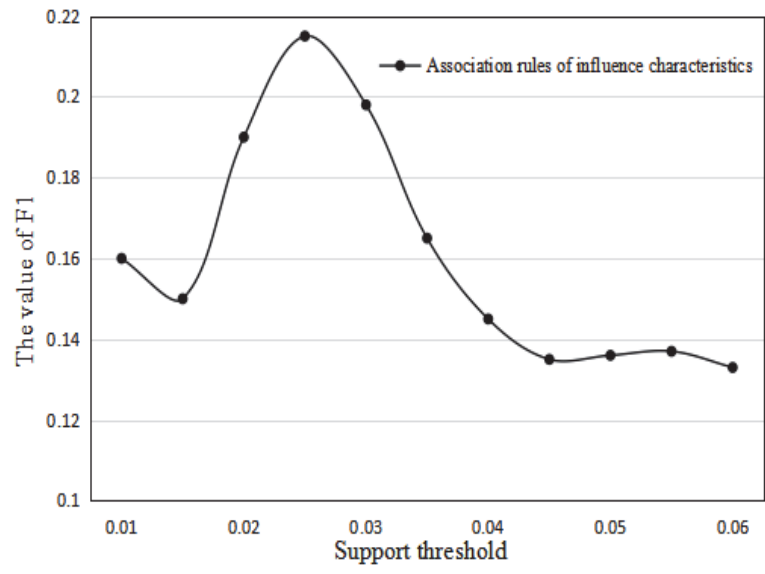

(a) Support threhsold

Figure 7 Relationship between support threhsold, confidence threshold, and $F 1$ value
Table 5 The PVEs and CPVEs of key indices

\begin{tabular}{|c|c|c|c|}
\hline Component & Eigen value & PVE / \% & CPVE / \% \\
\hline Principal component 1 & 7.5429 & 0.2662 & 64.241 \\
\hline Principal component 2 & 5.4381 & 0.1819 & 76.456 \\
\hline Principal component 3 & 3.9164 & 0.1382 & 87.287 \\
\hline Principal component 4 & 2.1772 & 0.0758 & 96.473 \\
\hline Principal component 5 & 1.9618 & 0.0682 & 97.480 \\
\hline Principal component 6 & 1.9426 & 0.0685 & 98.633 \\
\hline Principal component 7 & 1.8056 & 0.0624 & 98.996 \\
\hline Principal component 8 & 1.5414 & 0.0532 & 99.933 \\
\hline Principal component 9 & 1.0045 & 0.0354 & 99.996 \\
\hline Principal component 10 & 1.0013 & 0.0353 & 100.00 \\
\hline
\end{tabular}

The 40 indices were ranked by their PVEs. The CPVE of the top 10 principal components reached $98.51 \%$.The indices corresponding to the ten principal components were treated as the key indices, and sorted in descending order as: shedding probability of system voltage, out-oflimit probability of system voltage, expectation of system power shortage, availability of system power supply, safety margin of regional current, safety probability of regional current, lower limit of safety margin of node voltage, upper limit of safety margin of node voltage, safety probability of component voltage safety probability, and safety margin of component voltage.

To disclose the correlation between the support threshold and the number of association rules. Different thresholds and threshold intervals were configured to compute the $F 1$-score of the final recommendation. The support interval was set to 0.01 , and the confidence interval was set to 0.1 .

As shown in Fig. 7a, the $F 1$ value increased with the support threshold, peaking at the threshold of 0.026. As the threshold grew, the number of indies for association rules was reduced, but the evaluation quality and efficiency were on the rise. The optimal mining effect was achieved at the threshold of 0.026 , which was taken as the support threshold for the following analysis.

Next, different confidence thresholds were set to verify the quality of association rules with the number of indices. As shown in Fig. 7b, the $F 1$ value slightly increased with the growing confidence threshold. The largest F1 was observed at the threshold of 0.122 . Thus, the quality of association rule mining improves with the increase of the confidence threshold, and reaches the optimal state at the threshold of 0.122 .

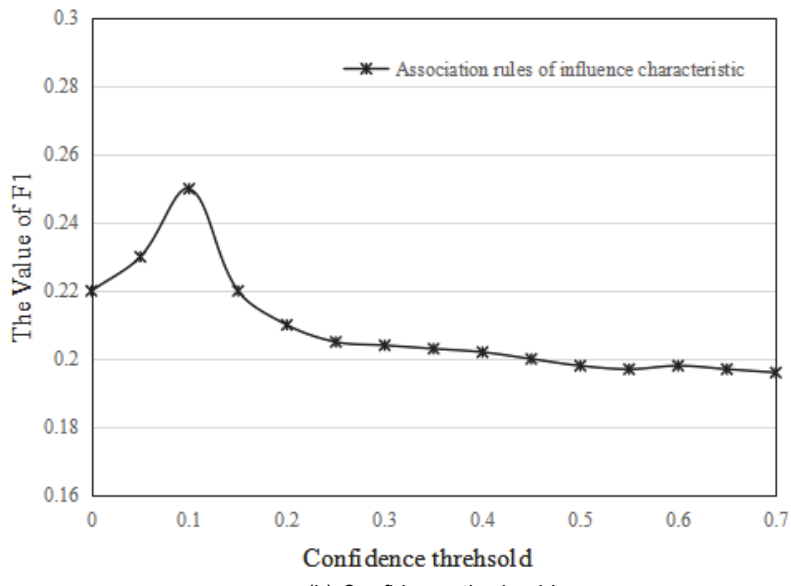

(b) Confidence threhsold 


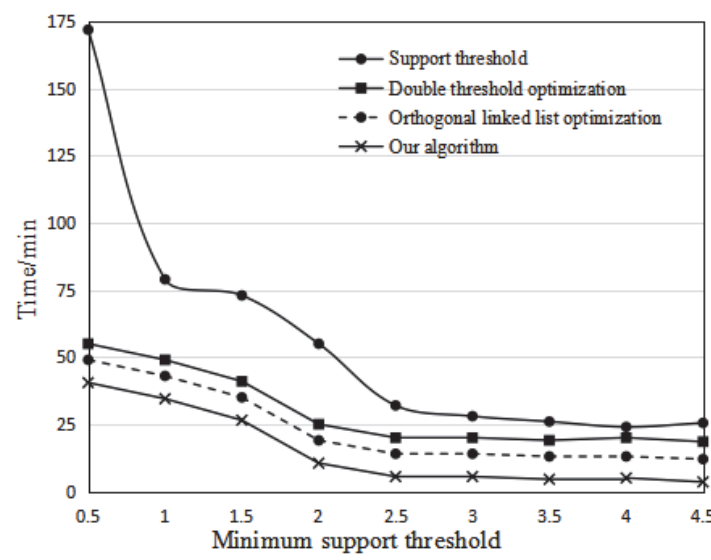

(a) Minimum support threshold

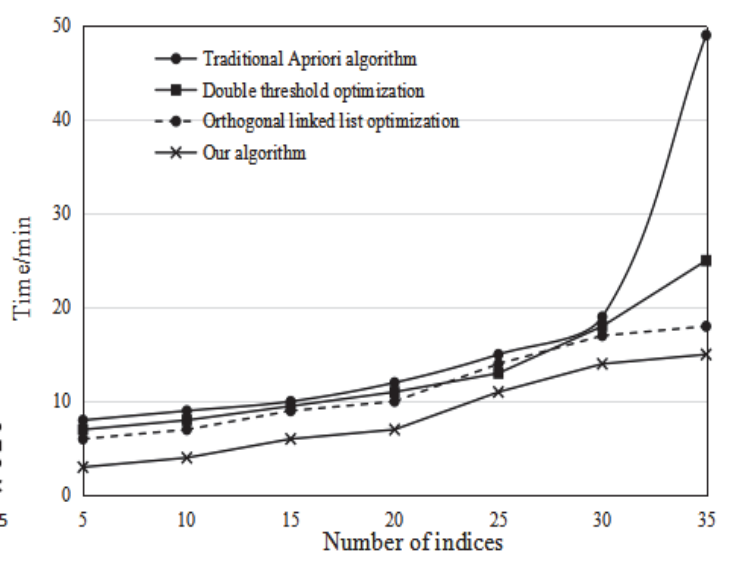

(b) Number of indices

Figure 8 Relationship between minimum support threshold, number of indices, and generation time of frequent itemsets

Table 6 Reliability parameters of system components

\begin{tabular}{|c|c|c|}
\hline Component & $\begin{array}{c}\text { Failure rate } \\
\text { (times / year) }\end{array}$ & $\begin{array}{c}\text { Failure duration / } \\
\mathrm{h}\end{array}$ \\
\hline DC bus & $0.0016 \mathrm{~km}$ & 2.5 \\
\hline DC cable & $0.055 \mathrm{~km}$ & 28 \\
\hline DC/AC module & 0.0065 & 24 \\
\hline DC transformer & 0.4518 & 15 \\
\hline AC transformer & 0.0094 & 240 \\
\hline DC/DC module & 0.0088 & 18 \\
\hline DC circuit breaker & 0.4775 & 14 \\
\hline Converter station & 3.4179 & 9 \\
\hline Energy storage system & 0.2172 & 24 \\
\hline Wind power generation system & 2.4078 & 600 \\
\hline PV system & 0.0081 & 38 \\
\hline
\end{tabular}

To validate the proposed association rule mining algorithm, comparative experiments were conducted against traditional Apriori algorithm [9, 10], double threshold optimization [12], and orthogonal linked list optimization [14]. As shown in Fig. 8, the generation time of frequent itemsets decreased with the increase of support threshold, when the number of indices was fixed. Our algorithm consumed the shortest time among all contrastive algorithms. When the support threshold was fixed, the generation time of frequent itemsets decreased with the growing number of indies. Our algorithm still consumed shorter time than the other algorithms. The comparison fully demonstrates the effectiveness and efficiency of our algorithm.

Table 7 User load parameters

\begin{tabular}{|c|c|c|c|c|}
\hline $\begin{array}{c}\text { Load } \\
\text { point }\end{array}$ & $\begin{array}{c}\text { Number of } \\
\text { users }\end{array}$ & $\begin{array}{c}\text { Mean load / } \\
\text { MW }\end{array}$ & Load type & $\begin{array}{c}\text { Load shedding } \\
\text { priority }\end{array}$ \\
\hline U1 & 12 & 12.128 & Class IV & Level 1 \\
\hline U2 & 10 & 21.941 & Class IV & Level 2 \\
\hline U3 & 12 & 15.644 & Class IV & Level 3 \\
\hline U4 & 13 & 14.593 & Class III & \\
\hline U5 & 11 & 12.478 & Class I & \\
\hline U6 & 9 & 11.647 & Class I & \\
\hline U7 & 14 & 22.433 & Class II & \\
\hline U8 & 12 & 24.452 & Class III & \\
\hline
\end{tabular}

The selected DC distribution system mainly includes a wind power generation system, a PV system, an energy storage, 8 load points, 93 users, and several other components. Tabs. 6 and 7 provide the reliability parameters of system components and user loads, respectively.

Tab. 8 lists the evaluated supply reliabilities of user loads. It can be seen that our model can clearly obtain the correlations of failure rate and duration at each load node with the mean failure duration, an indicator of system reliability, through Bayesian network simulation.

Under the assumption that the system fails, the conditional probabilities of device failure and user load failure were computed with the aid of Bayesian network (Fig. 5). Fig. 9 shows the evaluated values of some distribution areas. It can be seen that, in the distribution areas, the supply reliabilities of load points U1, U2, U4, U7, U8, U9, and U12 were significantly affected by devices E1, E2, E3, E4, E5, E11, and E14. When the distribution system failed, E1 and E11 were the most likely to fail, that is, the user loads powered by the two devices had the highest failure probabilities. It is necessary to adjust the demand management to reduce the number of failures, making the system more reliable.

Table 8 Evaluated supply reliabilities of user loads

\begin{tabular}{|c|c|c|c|}
\hline Load point & Failure rate / times/year & $\begin{array}{c}\text { Mean } \\
\text { outage } \\
\text { duration / } \mathrm{h}\end{array}$ & $\begin{array}{c}\text { Mean fault } \\
\text { duration / } \\
\mathrm{h} / \text { time }\end{array}$ \\
\hline $\mathrm{U} 1$ & 1.398 & 6.475 & 4.5 \\
\hline $\mathrm{U} 2$ & 1.345 & 7.548 & 5 \\
\hline $\mathrm{U} 3$ & 1.473 & 5.492 & 6 \\
\hline $\mathrm{U} 4$ & 1.279 & 4.744 & 6 \\
\hline $\mathrm{U} 5$ & 1.376 & 11.471 & 8.5 \\
\hline $\mathrm{U} 6$ & 1.687 & 5.479 & 3.5 \\
\hline $\mathrm{U} 7$ & 1.437 & 8.924 & 6.5 \\
\hline $\mathrm{U} 8$ & 1.491 & 9.472 & 8 \\
\hline
\end{tabular}

In the selected distribution system, there is a high presence of distributed generation. The greater the proportion of distributed generation, the key metrics of system reliability, such as mean outage frequency and mean failure duration, will both decline. Tab. 9 presents the predicted system reliability before and after the operation of distributed generation. Obviously, the grid-access of distributed generation greatly enhanced the supply reliability of the distribution system.

Table 9 System reliabilities before and after the grid-access of distributed generation

\begin{tabular}{|c|c|c|}
\hline Item & $\begin{array}{l}\text { Before grid- } \\
\text { access }\end{array}$ & $\begin{array}{l}\text { After grid- } \\
\text { access }\end{array}$ \\
\hline $\begin{array}{c}\text { Mean outage frequency of the system / } \\
\text { times/(household·year) }\end{array}$ & 5.5126 & 1.4215 \\
\hline $\begin{array}{c}\text { Mean duration of system outages / } \\
\text { times/(households } \cdot \text { year) }\end{array}$ & 14.6658 & 9.4228 \\
\hline Mean outage duration / H/time & 12.8684 & 7.1487 \\
\hline Mean availability of power supply & 0.9642 & 0.9845 \\
\hline Low battery expectation / MWh/ year & 80.5479 & 84.2721 \\
\hline
\end{tabular}



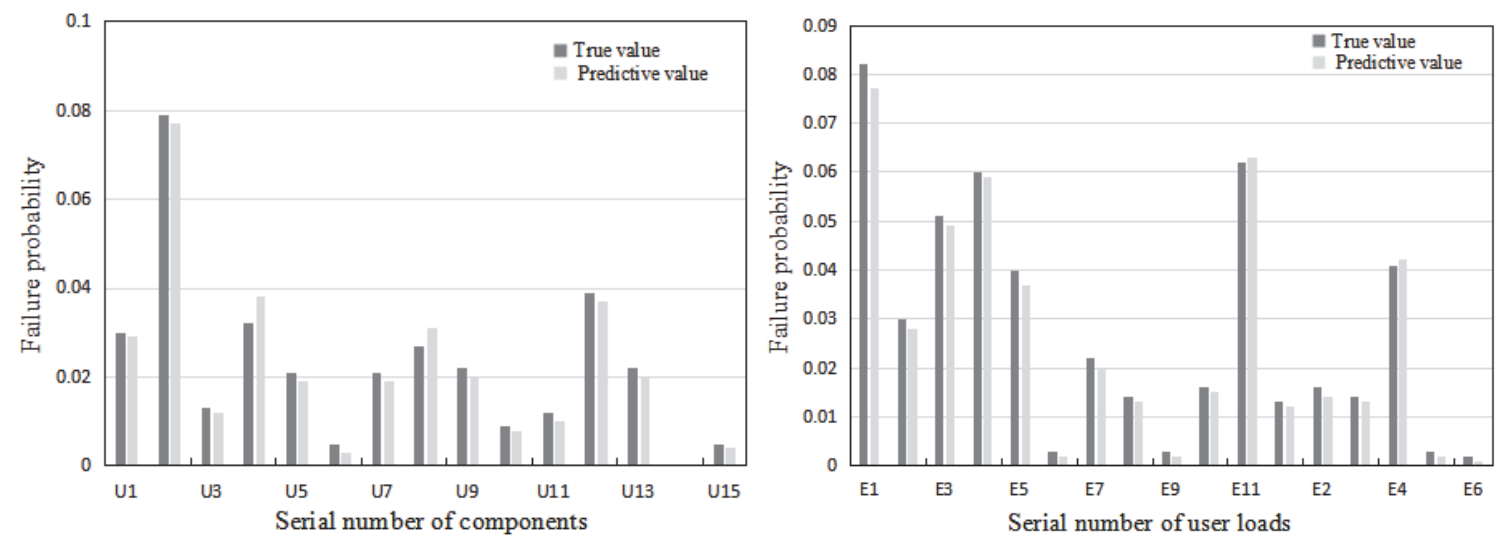

Figure 9 Predicted failure probabilities of some devices and user loads

\section{CONCLUSIONS}

The DC distribution mode could significantly promote the energy conservation and supply efficiency of the distribution system in intelligent buildings. But the stochastic and intermittent power produced by distributed generation, and the instability of key supply and distribution devices in the system pose many problems to the system operation. Therefore, this paper proposes an evaluation model for the reliability of the distribution system for intelligent buildings, by virtue of the advantage of big data mining in data analysis and processing. After setting up an evaluation index system from the level dimension and the degree dimension, the authors identified the key indices through the PCA, and mined the association rules from the original data on system reliability based on MapReduce. Next, the reliabilities of key components in the system were modeled, followed by a time series simulation of the system with Bayesian network. In addition, the flow of our system reliability evaluation algorithm was explained in details. After that, our algorithm was compared with traditional Apriori algorithm, double threshold algorithm, and orthogonal linked list algorithm through experiments. The results show that our approach can ideally evaluate system reliability.

\section{Acknowledgements}

Project Supported by Qinglan Project for the University Key Teacher from Jiangsu Education Department (2020); The Natural Science Foundation of the Jiangsu Higher Education Institutions (19KJB470018); The Science and Technology Project of Jiangsu Province Construction System (2018ZD065); The Key Research and Development Program of the $\mathrm{Xu}$ Zhou Municipal (KC19224).

\section{REFERENCES}

[1] Escalera, A., Hayes, B., \& Prodanović, M. (2018). A survey of reliability assessment techniques for modern distribution networks. Renewable and Sustainable Energy Reviews, 91, 344-357. https://doi.org/10.1016/j.rser.2018.02.031

[2] Sahour, A., Boumehrez, F., Benouaret, M., \& Mokhneche, A. (2021). Greenhouse climate controller by using of internet of things technology and fuzzy logic. Instrumentation Mesure Métrologie, 20(1), 29-38.

https://doi.org/10.18280/i2m.200105
[3] Wang, Y. (2017). Analytical complex distribution system reliability evaluation considering stochastic interruption durations and network reconfigurations. Electric Power Components and Systems, 45(19), 2151-2163. https://doi.org/10.1080/15325008.2017.1361484

[4] Al Hourani, A. \& Al Muhaini, M. (2016). Impact of demand side management on the reliability performance of power distribution systems. In 2016 Saudi Arabia Smart Grid (SASG), 1-5. https://doi.org/10.1109/SASG.2016.7849661

[5] Li, G., Bie, Z., Xie, H., \& Lin, Y. (2016). Customer satisfaction based reliability evaluation of active distribution networks. Applied energy, 162, 1571-1578. https://doi.org/10.1016/j.apenergy.2015.02.084

[6] Peng, Z. M. (2020). An operation and maintenance strategy of intelligent building information model data based on cloud computing. Ingénierie des Systèmesd' Information, 25(4), 461-467. https://doi.org/10.18280/isi.250408

[7] Liu, J. L. \& Li, K. (2020). Design of an intelligent symptom differentiation and electrical stimulation rehabilitation system. Journal Européen des Systèmes Automatisés, 53(5), 681-693. https://doi.org/10.18280/jesa.530511

[8] Heidari, A., Agelidis, V. G., Zayandehroodi, H., Pou, J., \& Aghaei, J. (2015). On exploring potential reliability gains under islanding operation of distributed generation. IEEE Transactions on Smart Grid, 7(5), 2166-2174. https://doi.org/10.1109/TSG.2015.2462115

[9] Reinders, A. (2018). Perceived and reported reliability of the electricity supply at three urban locations in Indonesia. Energies, 11(1), 140. https://doi.org/10.3390/en11010140

[10] Kamyab, G. (2020). Optimal feeder routing and DG placement using Kruskal's algorithm. European Journal of Electrical Engineering, 22(1), 71-78. https://doi.org/10.18280/ejee.220109

[11] Wang, X. (2016). Structural reliability analysis of modular multi-level converters. Proceedings of the CSEE, 36(7), 1908-1914. https://doi.org/10.13334/j.02588013.pcsee.2016.07.018

[12] Yu, S. U. N., Bollen, M., \& Ault, G. (2008). Reliability Analysis of Islanded Distribution Systems with Distributed Energy Resourses. Power System Technology, 32(33), 7781.

[13] Ghods, A., Khaboury, D. A., \& Zakerifar, R. (2009). Case study of distribution network reliability analysis based on probabilistic method. 41 ${ }^{\text {st }}$ North American Power Symposium, 1-7. https://doi.org/10.1109/NAPS.2009.5484018

[14] Costa, P. M. \& Matos, M. A. (2009). Assessing the contribution of microgrids to the reliability of distribution networks. Electric Power Systems Research, 79(2), 382-389. https://doi.org/10.1016/j.epsr.2008.07.009

[15] Shi, Q., Xu, X., \& Zhao, Y. (2016). Effects of power electronic devices on DC distribution reliability. Power System Technology, 40(3), 725-732. 
[16] Li, J. (2018). DC Distribution networks reliability evaluation and prediction based on Sequential Monte Carlo method. Solar Energy, 39, 154-162.

[17] He, Y., Liu, D., Zeng, C., \& Wen, M. (2011). Novel model and multistage algorithm for distribution network reconfiguration considering system reliability. Dianli Xitong Zidonghua (Automation of Electric Power Systems), 35(17), 56-60.

[18] Munoz-Delgado, G., Contreras, J., \& Arroyo, J. M. (2017). Distribution network expansion planning with an explicit formulation for reliability assessment. IEEE Transactions on Power Systems, 33(3), 2583-2596. https://doi.org/10.1109/TPWRS.2017.2764331

[19] Liu, Q. Z., Tong, B. B., Li, D. L., Lu, Y., Fu, Y. H., Chen, L., \& Zhao, K. Y. (2020). A smart and safe electricity consumption model for integrated energy system based on electric big data. International Journal of Safety and Security Engineering, 10(4), 529-534. https://doi.org/10.18280/ijsse.100412

[20] Wang, B., Li, Y., \& Watada, J. (2013). Supply reliability and generation cost analysis due to load forecast uncertainty in unit commitment problems. IEEE Transactions on Power Systems, 28(3), 2242-2252. https://doi.org/10.1109/TPWRS.2013.2238561

[21] Rudin, C., Ertekin, Ş., Passonneau, R., Radeva, A., Tomar, A., Xie, B., \& McCormick, T. (2014). Analytics for power grid distribution reliability in New York City. Interfaces, 44(4), 364-383. https://doi.org/10.1287/inte.2014.0748

[22] Wang, F., Xu, H., Xu, T., Li, K., Shafie-Khah, M., \& Catalão, J. P. (2017). The values of market-based demand response on improving power system reliability under extreme circumstances. Applied energy, 193, 220-231. https://doi.org/10.1016/j.apenergy.2017.01.103

[23] Gerber, D. L., Vossos, V., Feng, W., Marnay, C., Nordman, B., \& Brown, R. (2018). A simulation-based efficiency comparison of AC and DC power distribution networks in commercial buildings. Applied Energy, 210, 1167-1187. https://doi.org/10.1016/j.apenergy.2017.05.179

[24] Emjedi, M. R., Awodele, K., Chowdhury, S., \& Chowdhury, S. P. (2010). Reliability evaluation of distribution networks using fuzzy logic. IEEE PES General Meeting, 1-8. https://doi.org/10.1109/PES.2010.5589702

[25] Moshkbar-Bakhshayesh, K., Mohtashami, S., \& Sahraeian, M. (2021). Estimating buildup factor of alloys based on combination of Monte Carlo method and multilayer feedforward neural network. Annals of Nuclear Energy, 152, 108023. https://doi.org/10.1016/j.anucene.2020.108023

\section{Contact information:}

\section{Chenxi JIA}

(Corresponding author)

School of Intelligent Manufacturing,

Jiangsu Vocational Institute of Architectural Technology,

Xuzhou 221116, China

E-mail: 10758@jsjzi.edu.cn

\section{Hongyuan DING}

School of Intelligent Manufacturing,

Jiangsu Vocational Institute of Architectural Technology,

Xuzhou 221116, China

E-mail: dhy200095@foxmail.com

\section{Xing ZHANG}

School of Intelligent Manufacturing

Jiangsu Vocational Institute of Architectural Technology,

Xuzhou 221116, China

E-mail: 750731105@qq.com 